\title{
Review
}

\section{Complementary and Alternative Medicine for Chronic Prostatitis/Chronic Pelvic Pain Syndrome}

\author{
Jillian L. Capodice, Debra L. Bemis, Ralph Buttyan, Steven A. Kaplan and Aaron E. Katz \\ Department of Urology, College of Physicians and Surgeons, Columbia University Medical Center, New York, NY, USA
}

To discuss challenges concerning treatment for chronic prostatitis/chronic pelvic pain syndrome (CP/ CPPS) and review complementary and alternative medical (CAM) therapies being evaluated for this condition, we performed a comprehensive search of articles published from 1990-2005 using the PubMed, Medline databases. Data from the articles were abstracted and pooled by subject. Keywords cross-searched with CP/CPPS included: complementary, alternative, integrative, therapies, interventions, nutrition, antioxidants, herbs, supplements, biofeedback and acupuncture. Listed articles with no abstracts were not included. Various CAM therapies for CP/CPPS exist including biofeedback, acupuncture, hyperthermia and electrostimulation. Additionally, a variety of in vitro and in vivo studies testing herbal and nutritional supplements were found. Saw palmetto, cernilton and quercetin were the most frequently tested supplements for CP/CPPS. Although many CAM therapies demonstrate positive preliminary observations as prospective treatments for CP/CPPS, further exploratory studies including more randomized, controlled trials are necessary for significant validation as treatment options for this complex disorder.

Keywords: acupuncture - alternative medicine - biofeedback - chronic prostatitis - complementary medicine - herbs - hyperthermia - supplements

\section{Introduction and Characterization of Prostatitis}

Chronic prostatitis/chronic pelvic pain syndrome (CP/CPPS) is of significant interest in urology and accounts for up to 2 million office visits per year (1). Currently, there are multiple approaches to the management of CP/CPPS depending on the classification of the related symptoms. However, there are no absolute findings or laboratory tests employed and diagnosis is often one of exclusion.

In 1995, the National Institutes of Health established an International Prostatitis Collaborative Network in order to construct a new classification of prostatitis syndromes and better define chronic prostatitis $(2,3)$. The categories are now

\footnotetext{
For reprints and all correspondence: Jillian L. Capodice, MS, L.Ac, Department of Urology, College of Physicians and Surgeons, Columbia University Medical Center, Herbert Irving Pavilion, 11th Floor, 161 Fort Washington Avenue, New York, NY 10032, USA. Tel: +1-212-305-5727; Fax: +1-212-305-1564; E-mail: jc2346@columbia.edu
}

documented as follows:

Category 1. Acute bacterial prostatitis

Category 2. Chronic bacterial prostatitis

Category 3. Chronic prostatitis/chronic pelvic pain syndrome

A. Inflammatory

B. Non-inflammatory

Category 4. Asymptomatic inflammatory prostatitis.

While most patients report a primary subjective symptom of local pain and/or dysuria, the clinical presentation of acute versus chronic prostatitis varies. Laboratory cultures are standardly employed to detect bacterial involvement and this testing along with other diagnostic criteria determines each classification. Men with Category 1, acute prostatitis, frequently present with dysuria, fever, malaise, myalgia (non-specific) and positive culture analysis that often reveals coliform bacteria. This imparts to standard antibiotic treatment with good prognosis for recovery and minimal recurrence.

(C) The Author (2005). Published by Oxford University Press. All rights reserved.

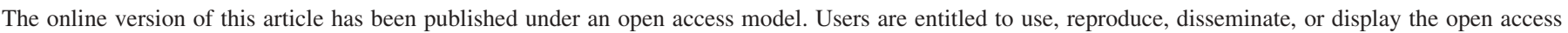

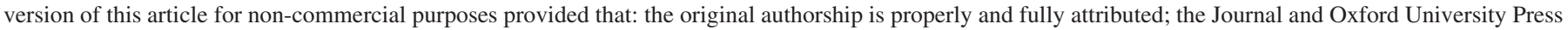

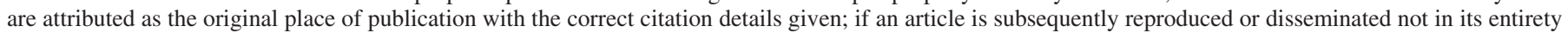
but only in part or as a derivative work this must be clearly indicated. For commercial re-use, please contact journals.permissions@oxfordjournals.org 
Patients with Category 2, chronic bacterial prostatitis, present with similar symptoms as those with acute prostatitis. However, the frequency of symptoms (duration $>3$ months), recurrent urinary tract infections and additional diagnostic tests including analysis of lower urinary tract cultures contribute to its diagnosis as Category 2 prostatitis (2).

Men with Category 4, asymptomatic inflammatory prostatitis, do not present with subjective symptoms. This diagnosis is often discovered via laboratory findings such as the positive presence of white blood cells in prostatic secretions or in prostate tissue during routine evaluation for other disorders (1).

Comparative to the total number of prostatitis cases reported, the majority of representative cases are Category $3, \mathrm{CP} /$ CPPS $(1,4)$. This diagnosis is usually one of exclusion, as bacterial etiology acute or chronic is ruled out. Other exclusion criteria include urogenital cancer, urethral stricture and neurologic disease affecting the bladder. However, the patient may still present with polyuria, dysuria, generalized myalgia or specific pelvic pain, urethral discharge, voiding dysfunction, sexual dysfunction and negative impact on quality-of-life (QOL). The presentation of this symptom set is now termed Category 3, CP/CPPS. Categories $3 \mathrm{~A}$ and $3 \mathrm{~B}$ are further differentiated by the presence or absence of inflammatory blood cells in prostatic secretions and seminal fluid, respectively $(4,5)$. Table 1 further outlines the characteristics and treatment options of Category 3 prostatitis.

Due to the complexity in diagnosing CP/CPPS, the National Institutes of Diabetes and Digestive and Kidney Diseases funded the Chronic Prostatitis Collaborative Research Network (CPCRN) in 1995 (2,3). This network was fundamental in the construction and validation of the National Institutes of Health Chronic Prostatitis Symptom Index (NIH-CPSI), which was implemented in 1999 (3). The index has become a valid measure that quantifies the qualitative experience of men with CP/CPPS and addresses three different aspects of CP/CPPS: pain, function and QOL $(3,6)$.
The formation of the CPCRN and the advent of the NIHCPSI have better characterized diagnosis and treatment for $\mathrm{CP} / \mathrm{CPPS}$, but challenges still exist. While standard treatment options including anti-inflammatory agents, analgesics and alpha-blockers are often prescribed, impact on QOL is another factor often overlooked in the treatment and management of CP/CPPS $(1,4,5,7)$. The focus on QOL, anecdotal data, epidemiological studies and the increased popularity and validation of herbal, complementary and alternative medicine (CAM) has led to exploration of the utility of CAM therapies as treatments for CP/CPPS (8). CAM therapies including biofeedback, acupuncture, heat therapy, electrostimulation, herbal and nutritional supplements will be discussed below.

\section{CAM Background}

CAM, as defined by the National Center for Complementary and Alternative Medicine (NCCAM), is a group of diverse medical and health care systems, practices and products that are not presently considered part of conventional medicine. Conventional medicine is further defined as medicine as practiced by holders of MD (medical doctor) or DO (doctor of osteopathy) degrees (9). Though the list of what therapies or practices considered to be CAM changes continually, the pool of both practitioners of CAM modalities and patients utilizing CAM services continues to grow within the United States and globally (9).

The inclusion of CAM practices in urology is also being implemented in the clinic. Many groups such as the Committee of Complementary and Alternative Medicine within the American Urological Association (AUA) recognize the integration of non-conventional therapies into urological clinical practice. Additionally, both public demand for CAM therapies and their testing and validation within health science research centers has increased $(8,10,11)$. It has been suggested that many urological conditions possessing subjective and QOL

Table 1. Characteristics and treatment options for CP/CPPS*

\begin{tabular}{|c|c|c|c|}
\hline Category 3 prostatitis & Definition & Standard options & CAM options \\
\hline $\begin{array}{l}\text { Category 3: Chronic prostatitis/ } \\
\text { chronic pelvic pain }\end{array}$ & $\begin{array}{l}\geq 3 \text { months pain/discomfort in the pelvic } \\
\text { region, no bacterial involvement, } \\
\text { inconsistent micturition and/or sexual } \\
\text { function complaints }\end{array}$ & Antibiotics & Acupuncture \\
\hline A. Inflammatory & $\begin{array}{l}\text { A. Presence of white blood cells in semen, } \\
\text { EPS or VB3 }\end{array}$ & Alpha-blockers & Biofeedback \\
\hline \multirow[t]{7}{*}{ B. Non-inflammatory } & $\begin{array}{l}\text { B. Absence of white blood cells in semen, } \\
\text { EPS or VB3 }\end{array}$ & Analgesics & Electrical stimulation \\
\hline & & Anti-inflammatory drugs & Heat therapy \\
\hline & & 5-Alpha reductase inhibitors & Herbal and nutritional agents \\
\hline & & Muscle relaxants & \\
\hline & & Pentosan polysulfate & \\
\hline & & Prostatic massage & \\
\hline & & Physical therapy & \\
\hline
\end{tabular}

CAM, Complementary and alternative medicine; EPS, expressed prostatic secretions; VB3, voided urine after prostatic massage.

*As adapted from the National Institutes of Health/National Institutes of Diabetes and Digestive and Kidney Diseases (1-3). 
components such as in benign prostatic hyperplasia (BPH), chronic prostatitis, voiding, erectile dysfunction and cancer prevention and survivorship might be particularly amenable to CAM treatment strategies (10). This review will focus on current CAM therapies found in the literature for $\mathrm{CP} / \mathrm{CPPS}$.

\section{CAM Therapies for CP/CPPS}

\section{Biofeedback}

Biofeedback therapy is considered a mind-body technique that utilizes a monitoring machine to assist people in controlling bodily functions such as heart rate, blood pressure and muscle tension. This therapy has been studied for its efficacy in urological conditions such as incontinence, prolapse, pediatric voiding dysfunction and CP/CPPS (12-17). The hypothesis of biofeedback's mechanism of action in treating CP/CPPS is based on the principle that maximum muscle contraction prompts maximum muscle relaxation. This mechanism addresses the chronic pain aspect of CP/CPPS and focuses on muscular reeducation, which may ultimately provide symptom relief (13-15).

Two studies testing the value of biofeedback therapy for CP/CPPS yielded positive results. The first study assessed 62 patients who were refractory to conventional therapy (such as antibiotics and/or alpha-blockers) for greater than half a year. These patients were treated utilizing the Urostym Biofeedback equipment five times a week for 2 weeks with a stimulus intensity of $15-23 \mathrm{~mA}$ and duration of $20 \mathrm{~min}$. The NIH-CPSI index noted a significant overall reduction in score $(P<0.01)$ and no side effects were reported during the trial (13).

A second pilot study evaluated biofeedback therapy in 19 men with pelvic floor tension and CP/CPPS. These results demonstrated significant improvement in pain scores as measured by the AUA symptom index $(P=0.001)$. While this study focused on testing the effect of biofeedback therapy in treating the symptoms associated with $\mathrm{CP} / \mathrm{CPPS}$, it also implicated the presence of pelvic floor tension contributing to pain and the paramount importance of muscular reeducation for its treatment (15). These initial, positive biofeedback studies may warrant larger randomized clinical trials to confirm safety and efficacy as well as explore the mechanism of action of biofeedback therapy.

\section{Acupuncture}

Acupuncture is a traditional Chinese method of medical treatment involving the insertion of fine, single-use, sterile needles in acupoints according to a system of channels and meridians that was developed by early practitioners of Traditional Chinese Medicine (TCM) over 2000 years ago. The needles are stimulated by manual manipulation, electrical stimulation or heat (18). Currently, acupuncture is often used with TCM and it is a recognized health profession with strict licensure and regulatory status in 40 states (19). Common applications include acupuncture as a complementary therapy for cancer patients undergoing chemotherapy or radiotherapy, for conditions involving pain such as migraines and back pain, and for relieving the impact of stress among patients with chronic conditions. The precise physiological mechanism of action of acupuncture is unknown but a variety of hypotheses exist. For example, acupuncture analgesia is thought to be mediated by central nervous system (CNS) mechanisms of pain control via the release of specific neurotransmitters, such as endorphins (20-23). Additionally, there are significant data which suggest that acupuncture treatment can decrease inflammation and relieve pain $(24,25)$.

Data suggesting the ability of acupuncture treatment to decrease pain, positively impact QOL and potentially modulate inflammation and/or affect the CNS has suggested it as potential therapeutic option for men with CP/CPPS. While a number of studies listed in other journals test the utility of acupuncture treatment for CP/CPPS (26) only two medline listed pilot studies are shown testing acupuncture treatment in patients with CP/CPPS.

The first study examined whether acupuncture improved pain, voiding symptoms and QOL in 12 men with CP/CPPS. This study reported a significant decrease in total NIH-CPSI pain, urinary and QOL scores $(P<0.05)$ over 6 weeks of treatment and an average 33 weeks of follow-up (27). The mechanism of action addressed in this paper suggests a neuropathic model of CP/CPPS and the hypothesis that acupuncture, if considered a neuromodulatory therapy, may provide a therapeutic option for men with CP/CPPS (27).

A second study tested acupuncture treatment for CP/CPPS patients with intrapelvic venous congestion. This study of 10 patients receiving 5 weeks of acupuncture treatment also reported a significant decease in NIH-CPSI pain and QOL scores $(P<0.05, P<0.01)$. While the study reported no serious adverse events, the mechanism of action was not addressed (28). The promising clinical outcome of both studies testing acupuncture for CP/CPPS implies that larger studies are required to confirm the utility of acupuncture in this patient population.

\section{High Frequency Electrostimulation}

Only one study in English was found utilizing electrostimulation for chronic prostatitis. This study tested a new, high frequency, urethral-anal prototype stimulation device in men with CP/CPPS twice weekly for 5 weeks. The results demonstrated a significant decrease in the NIH-CPSI $(P=0.0002)$ with no urethral, anal complaints or other side effects (29). The authors suggest that due to the positive results, simple technology and ability to be self-administered, this new device may have utility in the treatment of CP/CPPS. However, further studies and standardization of the electrostimulation device are essential.

\section{Hyperthermia}

Anecdotal evidence and a few clinical trials have suggested heat therapy or hyperthermia as a treatment option for men 
(a)

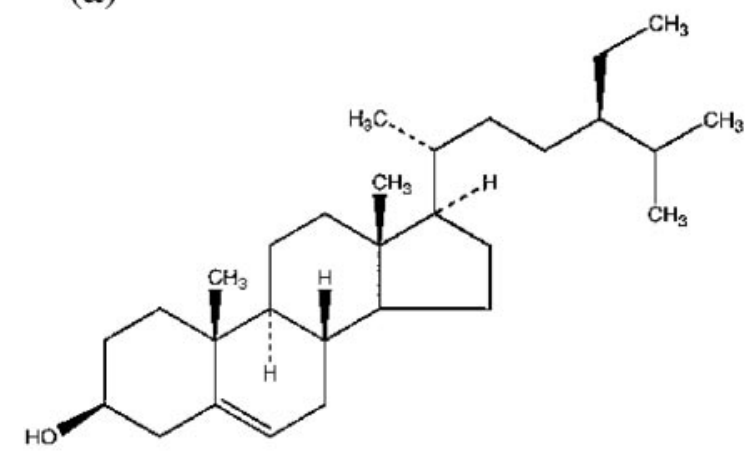

(b)<smiles>O=c1c(O)c(-c2ccc(O)c(O)c2)oc2cc(O)cc(O)c12</smiles>

Figure 1. Chemical structures of components found in herbal or nutritional supplements. (a) Structure of beta-sitosterol an active component of $S$. repens (41). (b) Structure of quercetin (41).

with CP/CPPS. Its mechanism of action is based on the application of heat to the prostate to relieve pain. An excellent review by Zeitlin (30) discusses the lack of literature concerning hyperthermia and CP/CPPS. The review notes a variety of pitfalls in hyperthermia research including variation and lack of standardization of treatment. These concerns are applicable to both the type of heat utilized such as interstitial heat or microwaves and variation in its application, either transrectally or transurethrally. The review also suggests that the hyperthermia instruments used were not validated and outcome measures were subjective. However, the review implies that utilization of a quantitative assessment tool, applied statistics and greater documentation of therapy type may offer hyperthermia a better opportunity to be evaluated as a potential therapy for CP/CPPS (30).

We also discovered the paucity of literature described by Zeitlin and only three listed clinical trials utilizing hyperthermia. The first study analyzed a group of 45 men with chronic abacterial prostatitis or prostadynia who underwent 6 weekly, $1 \mathrm{~h}$ sessions of local deep microwave hyperthermia $\left(42.5+/-0.5^{\circ} \mathrm{C}\right)$ to the prostate. Although the authors report encouraging results in the decrease of pain, these subjective patient assessments were not quantified by the NIH-CPSI or other index for CP/CPPS (31).

A second abstract discussed a randomized, sham-controlled comparative study utilizing transrectal microwave hyperthermia in 80 men with CP/CPPS. While this abstract noted a $75 \%$ symptomatic improvement in the treatment group, the study was available as an abstract only with no statistical significance or descriptive methodology reported (32). A third study also tested transrectal microwave hyperthermia for both chronic non-infectious and infectious prostatitis. While the study design incorporated obtaining measurement of prostatic secretions, uroflowmetry and transrectal color Dopplerographic mapping, the results from the study were not abstracted as the article was in Russian (33).

\section{Herbal and Nutritional Supplements}

Herbal and nutritional supplement therapies have been most widely investigated for their utility in CP/CPPS and other prostate conditions such as BPH (34-40). While many formulations have been cited for their use in a wide variety of urological conditions, saw palmetto, pollen extract and quercetin were the supplements found with specific application to CP/ CPPS. While most herbal and nutritional supplements contain a wide variety of synergistic ingredients upon compositional analysis, some of the active components such as phytosterols or antioxidants are listed in Fig. 1.

\section{Saw palmetto}

Saw palmetto (Serenoa repens) garnered much attention in urology based on a great deal of anecdotal evidence regarding its prostate specific properties. It is widely used in many Asian, African and European countries and compositional analysis of the berry of $S$. repens exhibits sterols and free fatty acids as its major constituents (41). Initial studies suggested that the efficacy of saw palmetto may be similar to that of the pharmaceutical enzyme inhibitors such as finasteride. This preliminary data prompted the exploration of mechanism, utility and efficacy of saw palmetto in in vitro analysis and in clinical trial settings. While a number of trials have examined saw palmetto use for symptoms related to BPH (34-39), only a few have focused on it specifically for CP/CPPS (42-44).

The first study compared the safety and efficacy of saw palmetto berry supplement versus finasteride in men with Category 3, CP/CPPS. This prospective, open label 1 year study randomized 64 men to the saw palmetto or finasteride group, respectively. After 1 year of treatment, the NIH-CPSI score decreased from 23.9 to 18.1 in the finasteride group $(P<0.003)$ and from 24.7 to 24.6 in the saw palmetto group $(P=0.41)$. While significance was only achieved in the finasteride treatment arm, it was notable that at the end of the trial 41 and $66 \%$ of participants opted to continue the therapies of saw palmetto and finasteride, respectively, regardless of achieved statistical significance (42).

The second clinical trial from China examined the effects of prostadyn sabale capsules containing saw palmetto berry in patients with CP/CPPS. While 125 men reported positive outcome and the NIH-CPSI was used as a primary end point, the article is only available in Chinese and the manufacturer, 
active constituents of the capsules and statistical significance was not reported (43).

A third multicenter study testing a saw palmetto abstract called Permixon analyzed the response of Permixon therapy in 61 patients with Category 3B prostatitis. While $65 \%$ of the Permixon group reported improvement based on the Patients Subjective Global Assessment (SGA), the total NIH-CPSI and the pain, voiding and QOL/impact domains of the NIHCPSI, statistical significance was not reported (44). Additionally, prostate volume was unchanged in both the treatment and control groups. While this multicenter study suggests that Permixon may provide clinical benefit for CP/CPPS 3B, the dosages and components of the Permixon product were not listed in the abstract.

The assessments of saw palmetto studies for CP/CPPS are far fewer than those for BPH. However, marked and continued progress in molecular studies, increased mechanistic data and more clinical trials in CP/CPPS are warranted to ascertain the utility and reproducibility of saw palmetto use in men with chronic prostatitis.

\section{Pollen Extract: Cernilton}

Pollen extract is traditionally collected from the flowers of various plant types and it contains carbohydrates, fat, protein, vitamins and minerals (41). The particular pollen extract named cernilton has been suggested to benefit a variety of urological conditions. Anecdotal evidence and references from traditional herbal texts have implicated cernilton's potent anti-inflammatory properties and potential in treating symptomatic relief of urinary pain and dysfunction often present in both CP/CPPS (41) and BPH $(45,46)$. In vitro studies demonstrate a variety of experimentation on this particular extract including histopathological analysis of its effect on cell proliferation, apoptosis, serum cytokines and testosterone $(47,48)$. The literature also lists quite a few clinical trials on pollen extract; however, five are in the Japanese language and one in the German language $(45,48-52)$. While many of these studies report the positive activity of pollen extract and suggest its usefulness for CP/CPPS, data from these studies were not abstracted due to unavailability and translation of the articles.

One available study testing pollen extract reported a 78\% favorable response of men with chronic prostatitis taking Cernilton ${ }^{\circledR}$ pollen extract at a dosage of 1 tablet TID for 6 months (53). While this study reported favorable results, the study was published in 1993 and similar subsequent larger phase clinical trials are not evident to further elucidate the possible utility of pollen extract in men with CP/CPPS.

\section{Quercetin}

Quercetin is known chemically as a mixture of 2-(3,4-dihydroxyphenyl)-3,5,7-trihydroxy-4H-1-benzopyran-4-one and $3,3^{\prime}, 4^{\prime}, 5,7$-pentahydroxy flavone. It belongs to a group of polyphenolic substances known as flavonoids and is a member of the class of flavonoids called flavonols. It is commonly found in the plant kingdom in the rinds and barks of certain foods such as onions, grapes and green tea (41). Since quercetin is thought to have antioxidant, anti-inflammatory, antiviral, immunomodulatory, anticancer, gastroprotective and antiallergy activities it has been studied for a variety of conditions (54-56).

One prospective, randomized, double-blind, placebocontrolled trial was performed to test the action of this bioflavonoid in men with CP/CPPS. This placebo-based study assessed 30 men with CP/CPPS to receive the bioflavonoid quercetin, $500 \mathrm{mg}$ twice daily or the placebo pill for 1 month. Significant change in the NIH-CPSI score was observed in the quercetin $(P=0.003)$ versus the placebo group, who had an insignificant mean improvement in the NIH-CPSI score (57). While this was the only clinical trial found testing quercetin for CP/CPPS, the positive outcome supports the need for further study including cost analysis of quercitin therapy in this patient population.

\section{Other Herbal Agents for Prostatitis}

Finally, a wide variety of herbal compounds not previously discussed were found during this review, many of which are commonly used in the TCM herbal material medica. Some of the compounds are Nan mi qing capsules containing Rheum palmatum and $R x$. astragalus memberanaceus, Ye Ju Hua Shuan, an herbal suppository of Flos Chrysanthemi Indici and a variety of other formulae or capsules of which the ingredients were not listed (58-62).

Initial in vitro studies examining some of the herbal compounds effects on markers of inflammation such as thromboxanes (TBX2) and 6-keto-PGF1- $\alpha$ are promising as the link between chronic inflammation in CP/CPPS is still under investigation (58). While the preliminary reports of additional herbal compounds are encouraging, a number of difficulties exist in the extraction of this data. Namely, the articles are in the Chinese or other language and data including the ingredients, constituents and other practices including good manufacturing are unable to be assessed. While this conundrum exists for many herbal agents despite their historical use in a variety of traditional herbal medicine systems, testing of safety and utility are still necessary. However, the variety of herbal agents available offers a large source to draw from and the possibility that other herbal products might be beneficial in the treatment of CP/CPPS.

\section{Conclusions}

A summary of the reviewed literature is outlined in Table 2 and a variety of CAM modalities tested in patients with $\mathrm{CP} /$ CPPS include practitioner-based therapies such as biofeedback, hyperthermia, acupuncture and electrostimulation, and biological-based therapies including herbal and nutritional supplements. As the challenges in treating this complex and chronic disorder remain, further evidence of efficacious CAM treatment options for men with CP/CPPS is needed. Thus far, promising data on the function and efficacy of certain 
Table 2. Summary of CAM therapies for prostatitis/chronic pelvic pain syndrome

\begin{tabular}{lllll}
\hline CAM therapy & $\begin{array}{l}\text { Total } \\
\text { number of } \\
\text { studies }\end{array}$ & $\begin{array}{l}\text { Positive } \\
\text { outcome } \\
\text { significance } \\
\text { achieved }\end{array}$ & $\begin{array}{l}\text { Positive } \\
\text { outcome outcome }\end{array}$ & $\begin{array}{l}\text { Negative Data not } \\
\text { assessed* }\end{array}$ \\
\hline Biofeedback & $n=2$ & 2 & & \\
Acupuncture & $n=2$ & 2 & 1 & $2 *$ \\
$\begin{array}{l}\text { High frequency } \\
\text { electrostimulation }\end{array}$ & $n=1$ & 1 & 2 & $2 * *$ \\
Hyperthermia & $n=3$ & & & \\
Saw palmetto & $n=3$ & & & \\
Pollen extract & $n=7$ & 1 & & \\
Quercetin & $n=1$ & 1 & & \\
Other herbal extracts & N/A & & & \\
\hline
\end{tabular}

*Data not abstracted in our review.

**Significance not achieved; however, $41 \%$ of patients opted to continue saw palmetto therapy.

CAM therapies suggest their potential as treatment options for this patient population. Further exploratory studies including more in vitro studies of herbal products, mechanistic data, cost analysis and randomized, controlled trials will assist in validation of certain CAM therapies as permanent treatment options for men with CP/CPPS $(63,64)$.

\section{References}

1. Schaeffer AJ. Etiology and management of chronic pelvic pain syndrome in men. Urology 2004;63:75-84.

2. Litwin MS. A review of the development and validation of the National Institutes of Health Chronic Prostatitis Symptom Index. Urology 2002;60:14-8.

3. Litwin MS, McNaughton-Collins M, Fowler FJ Jr, Nickel JC, Calhoun EA, Pontari MA, et al. The National Institutes of Health chronic prostatitis symptom index: development and validation of a new outcome measure. Chronic Prostatitis Collaborative Research Network. J Urol 1999;162: 369-75.

4. Kreiger JN, Ross SO, Penson DF, Riley DE. Symptoms and inflammation in chronic prostatitis/chronic pelvic pain syndrome. Urology 2002;60: 959-63.

5. Pontari MA, Ruggieri MR. Mechanisms in prostatitis/chronic pelvic pain syndrome. Urology 2004;172:839-45.

6. Schnider H, Ludwig M, Weidner W, Brahler E. Experience with different questionnaires in the management of patients with CP/CPPS: GPSS, IPSS, NIH-CPSI. World J Urol 2002;21:116-8.

7. Mehik A, Alas P, Nickel JC, Sarpola A, Helstrom PJ. Alfuzosin treatment for chronic prostatitis/chronic pelvic pain syndrome: a prospective, randomized, double-blind, placebo-controlled, pilot study. Urology 2003;62:425-9.

8. Shoskes DA, Manickam K. Herbal and complementary medicine in chronic prostatitis. World J Urol 2003;21:109-13.

9. National Center for Complementary and Alternative Medicine website. Retrieved from http://nccam.nih.gov

10. Hirsch IH. Integrative urology: a spectrum of complementary and alternative therapy. Urology 2000;56:185-9.

11. McClure M. An overview of holistic medicine and complementary and alternative medicine for the prevention and treatment of $\mathrm{BPH}$, prostatitis, and prostate cancer. World J Urol 2002;20:273-84.

12. Shei Dei Yang S, Wang CC. Outpatient biofeedback relaxation of the pelvic floor in treating pediatric dysfunctional voiding: a short-course program is effective. Urol Int 2005;74:118-22.

13. Ye ZQ, Cai D, Lan RZ, Du GH, Yuan XY, Chen Z, et al. Biofeedback therapy for chronic pelvic pain syndrome. Asian J Androl 2003;5:155-8.
14. Nadler RB. Bladder training biofeedback and pelvic floor myalgia. Urology 2002;60:42-3.

15. Clemens JQ, Nadler RB, Schaeffer AJ, Belani J, Albaugh J, Bushman W. Biofeedback, pelvic floor re-education, and bladder training for male chronic pelvic pain syndrome. Urology 2000;56:951-5.

16. Aukee P, Immonen P, Laaksonen DE, Laippala P, Pettinen J, Airaksinen O. The effect of home biofeedback training on stress incontinence. Obstet Gynecol Surv 2005;60:95-6.

17. Dorey G, Speakman M, Feneley R, Swinkels A, Dunn C, Ewings P. Pelvic floor exercises for treating post-micturition dribble in men with erectile dysfunction: a randomized controlled trial. Urol Nurs 2004;24:490-7.

18. Ellis A, Wiseman N, Boss K. Fundamentals of Chinese Acupuncture. Brookline, MA: Paradigm Publications, 1991.

19. National Certification Commission for Acupuncture and Oriental Medicine website, www.nccaom.org

20. Han J, Pomeranz B, Stux G. Scientific Bases of Acupuncture: Central Neurotransmitters and Acupuncture Analgesia. New York: Springer-Verlag, 1989, 7-33.

21. Clement-Jones V, McLoughlin L, Tomlin S, Besser GM, Rees LH, Wen HL. Increased beta-endorphin but not met-enkephalin levels in human cerebrospinal fluid after acupuncture for recurrent pain. Lancet 1980;2:946-9.

22. Pomeranz B, Chiu D. Naloxone blockade of acupuncture analgesia: endorphin implicated. Life Sci 1976;19:1757-62.

23. Ma S. Neurobiology of acupuncture: toward CAM. eCAM 2004;1:41-7.

24. Watkin H. Back pain - an integrated approach in primary care. Acupunct Med 2004;22:203-6.

25. Sekido R, Ishimaru K, Sakita M. Differences of electroacupunctureinduced analgesic effect in normal and inflammatory conditions in rats. Am J Chin Med 2003;31:955-65.

26. Yuting C. Clinical observation on combined treatment of 360 cases of prostatitis with acupuncture of Sishenchong point, etc. and selfdrafted prescription I, II, and III. World J Acupunct-Moxibustion 2000; $10: 1-4$.

27. Chen R, Nickel JC. Acupuncture ameliorates symptoms in men with chronic prostatitis/chronic pelvic pain syndrome. Urology 2003;61: 1156-9.

28. Honjo H, Kamoi K, Naya Y, Ukimura O, Kojima M, Kitkoji H, Miki T. Effects of acupuncture for chronic pelvic pain syndrome with intrapelvic venous congestion: preliminary results. Int J Urol 2004;11:607-12.

29. John H, Ruedi C, Kotting S, Schmid DM, Fatzer M, Hauri D. A new high frequency electrostimulation device to treat chronic prostatitis. J Urol 2003; 170:1275-7.

30. Zeitlin SI. Heat therapy in the treatment of prostatitis. Urology 2002;60: 38-40.

31. Servadio C, Leib Z. Chronic abacterial prostatitis and hyperthermia: a possible new treatment? Br J Urol 1991;67:308-11.

32. Vassily O, Andrey S, Evgenii D, Otabek I, Boris L, Sergey R. Efficacy of transrectal microwave hyperthermia (TMRH) in the treatment of chronic prostatitis. A randomized sham controlled comparative study. J Urol 1999;161:33.

33. Sokolov AV. Transrectal microwave hyperthermia in the treatment of chronic prostatitis. Urologiia 2003;5:20-6.

34. Shoskes DA. Phytotherapy and other alternative forms of care for the patient with prostatitis. Curr Urol Rep 2002;3:330-4.

35. Lowe FC, Fagelman E. Phytotherapy for chronic prostatitis. Curr Urol Rep 2000;1:164-6.

36. Gordon AE, Shaughnessy AF. Saw palmetto for prostate disorders. Am Fam Physician 2003;67:1281-3.

37. Kaplan SA. Updated meta-analysis of clinical trials of Serenoa repens extract in the treatment of symptomatic benign prostatic hyperplasia. J Urol 2005; 173:516.

38. Vela-Navarrete R, Escribano-Burgos M, Farre AL, Garcia-Cardoso J, Manzarbeitia F, Carrasco C. Serenoa repens treatment modifies bax/ bcl-2 index expression and caspase- 3 activity in prostatic tissue from patients with benign prostatic hyperplasia. J Urol 2005;173:507-10.

39. Habib FK, Ross M, Ho CK, Lyons V, Chapman K. Serenoa repens (Permixon ${ }^{\circledR}$ ) inhibits the 5alpha-reductase activity of human prostate cancer cell lines without interfering with PSA expression. Int J Cancer 2005;114:190-4.

40. Gurley BJ, Gardner SF, Hubbard MA, Williams DK, Gentry WB, Carrier J, et al. In vivo assessment of botanical supplementation on human cytochrome P450 phenotypes: Citrus aurantium, Echinacea purpurea, milk thistle, and saw palmetto. Clin Pharmacol Ther 2004;76:428-40. 
41. Medical Economics (ed) Physician's Desk Reference (PDR) for Herbal Medicines. Montvale, NJ: Thomson Healthcare, 1998.

42. Kaplan SA, Volpe MA, Te AE. A prospective, 1-year trial using saw palmetto versus finasteride in the treatment of category III prostatitis/chronic pelvic pain syndrome. J Urol 2004;171:284-8.

43. Wu T, Zhang X, Wu R, Liu X. Effects of prostadyn sabale capsules on chronic prostatitis. Zhonghua Nan Ke Xиe 2004;10:337-99 (in Chinese).

44. Reissigl A, Pointner J, Marberger M, Remzi M, Brunner J, Obwexer S, Djavan B. Multicenter Austrian trial on safety and efficacy of phytotherapy in the treatment of chronic prostatitis/chronic pelvic pain syndrome. EAU 2004. Abstract 348.

45. Becker H, Ebeling L. Conservative therapy of benign prostatic hyperplasia (BPH) with Cernilton. Urologe 1988;28:301-6 (in German).

46. Buck AC, Cox R, Rees RW, Ebeling L, John A. Treatment of outflow tract obstruction due to benign prostatic hyperplasia with the pollen extract, cernilton: A double-blind, placebo-controlled study. Br J Urol 1990;66: 398-404.

47. Kamijo T, Sato S, Kitamura T. Effect of cernitin pollen-extract on experimental nonbacterial prostatitis in rats. Prostate 2001;49:122-31.

48. Asakawa K, Nandachi N, Satoh S, Honma M, Namikata S, Ishii M, et al. Effects of cernitin pollen-extract (Cernilton) on inflammatory cytokines in sex-hormone-induced nonbacterial prostatitis rats. Hinyokika Kiyo 2001;47:459-65 (in Japanese).

49. Horii A, Iwai S, Maekawa M, Tsujita M. Clinical evaluation of Cernilton in the treatment of the benign prostatic hypertrophy. Hinyokika Kiyo 1985;31:739-46 (in Japanese).

50. Ueda K, Jinno H, Tsujimura S. Clinical evaluation of Cernilton on benign prostatic hyperplasia. Hinyokika Kiyo 1985;31:187-91 (in Japanese).

51. Hayashi J, Mitsui H, Yamakawa G, Suga A, Kai A, Shimabukuro T, et al. Clinical evaluation of Cernilton in benign prostatic hypertrophy. Hinyokika Kiyo 1986;32:135-41 (in Japanese).

52. Maekawa M, Kishimoto T, Yasumoto R, Wada S, Harada T, Ohara T, et al. Clinical evaluation of Cernilton on benign prostatic hypertrophy-a multiple center double-blind study with Paraprost. Hinyokika Kiyo 1990;36:495-516 (in Japanese).

53. Rugendorff EW, Weidner W, Ebeling L, Buck AC. Results of treatment with pollen extract (Cernilton $\mathrm{N}$ ) in chronic prostatitis and prostatodynia. Br J Urol 1993;71:433-8.
54. Verbeek R, Plomp AC, van Tol EA, van Noort JM. The flavones luteolin and apigenin inhibit in vitro antigen-specific proliferation and interferongamma production by murine and human autoimmune T cells. Biochem Pharmacol 2004;68:621-9.

55. Alia M, Mateos R, Ramos S, Lecumberri E, Bravo L, Goya L. Influence of quercetin and rutin on growth and antioxidant defense system of a human hepatoma cell line (HepG2). Eur J Nutr 2005 (Epub ahead of print).

56. Mouat MF, Kolli K, Orlando R, Hargrove JL, Grider A. The effects of quercetin on SW480 human colon carcinoma cells: a proteomic study. Nutr J 2005;4:11.

57. Shoskes DA, Zeitlin SI, Shahed A, Rajfer J. Quercetin in men with category III chronic prostatitis: a preliminary prospective, double-blind, placebo-controlled trial. Urology 1999;54:960-3.

58. Dai CF, Zhang ZZ, Qi XL, Zhang MX, Li YP. Clinical and experimental study of treatment of nanmiqing capsule for chronic prostatitis. Zhonghua Nan Ke Xue 2002;8:379-82 (in Chinese).

59. Jia Y, Li Y, Li J, Sun M. Treatment of nonspecific chronic prostatitis with Qian Lie Xian Yan Suppository in 104 cases. J Tradit Chin Med 2001;21: 90-2.

60. Zhang Y, Liu Y. Study on treatment of blood stasis syndrome of chronic prostatitis using prostatitis decoction and its extract capsule. Zhongguo Zhong Xi Yi Jie He Za Zhi 1998;18:534-6 (in Chinese).

61. Zhang YQ, Liu YF, Yu LH. Effect of herbal prostatitis decoction on experimental prostatitis in rats. Zhong Xi Yi Jie He Za Zhi 1991;11: 480-1, 453-4 (in Chinese).

62. Kaneko S, Akiyama T, Kurita T. Combined treatment of chronic prostatitis with sulfamethoxazole-trimethoprim and hachimi-ji-oh-gan Hinyokika Kiyo. 1988;34:1091-5 (in Japanese).

63. McNaughton $\mathrm{C}$, Mac Donald $\mathrm{R}$, Wilt $\mathrm{T}$. Interventions for chronic abacterial prostatitis. Cochrane Database Syst Rev 2001;1: CD002080.

64. Propert KJ, Alexander RB, Nickel JC, Kusek JW, Litwin MS, Landis JR, et al. Design of a multicenter randomized clinical trial for chronic prostatitis/chronic pelvic pain syndrome. Urology 2002;59: $870-6$.

Received April 11, 2005; accepted September 12, 2005 


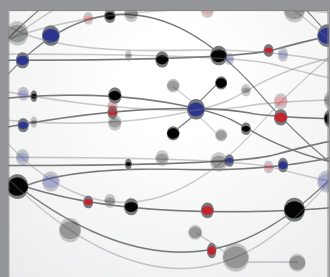

The Scientific World Journal
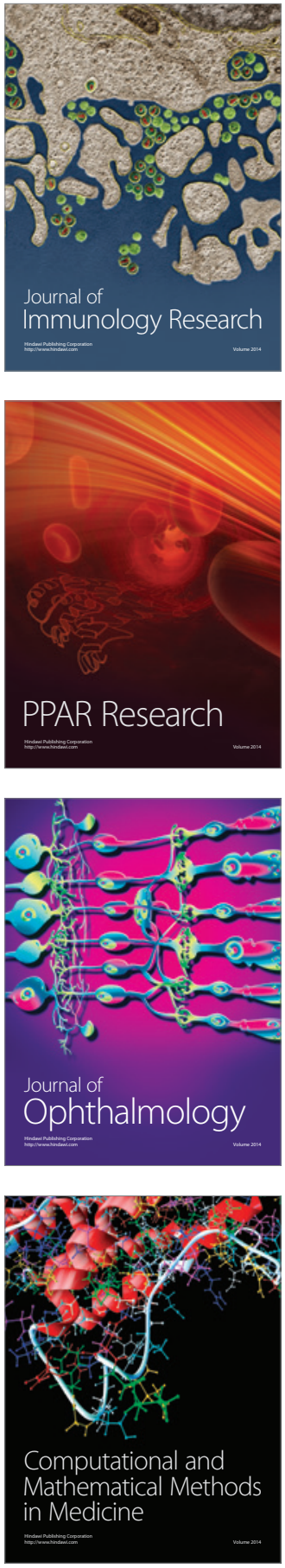

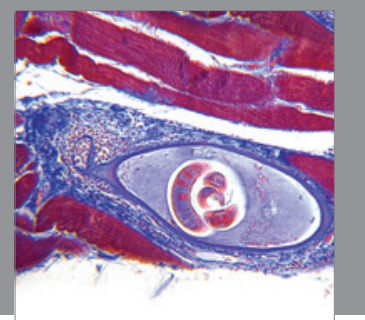

Gastroenterology

Research and Practice
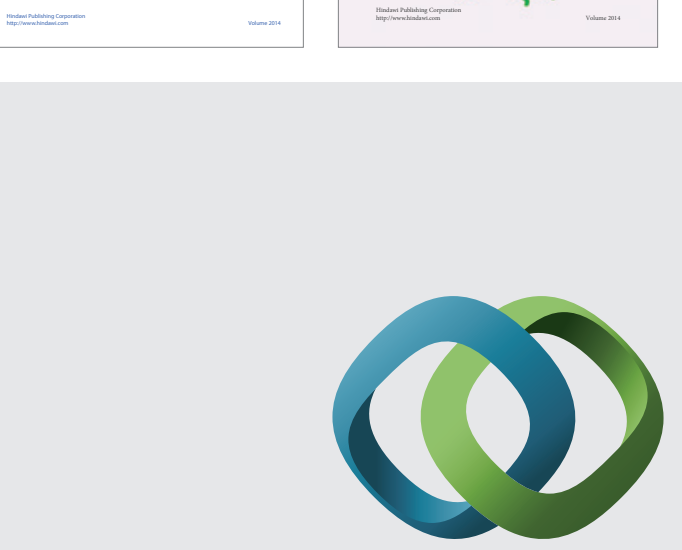

\section{Hindawi}

Submit your manuscripts at

http://www.hindawi.com
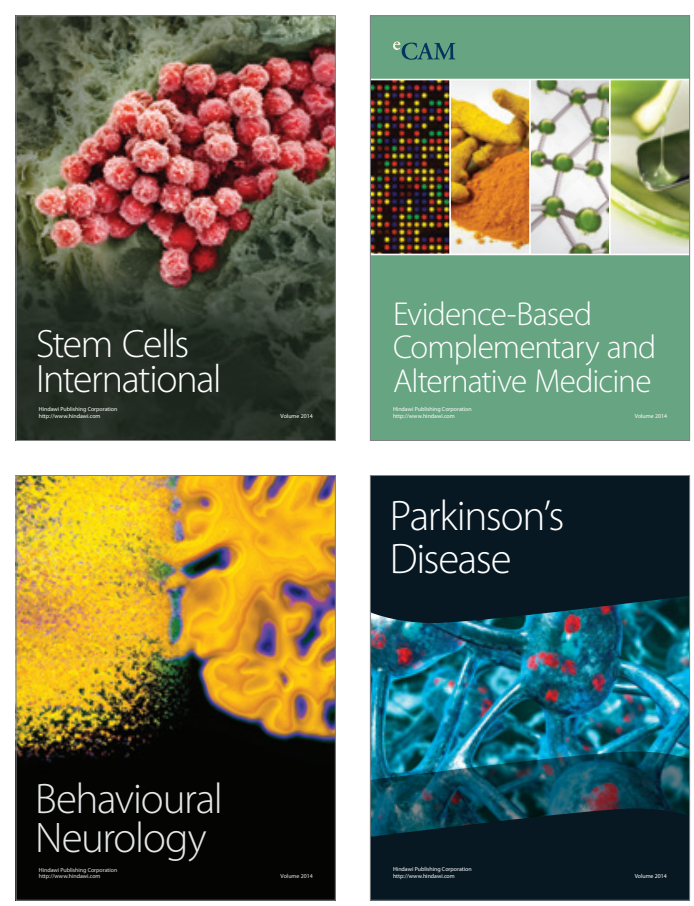

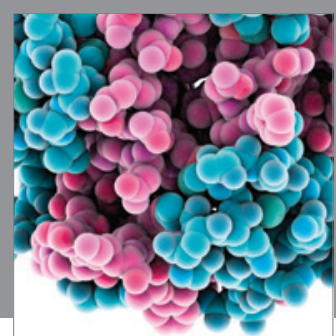

Journal of
Diabetes Research

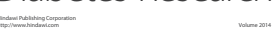

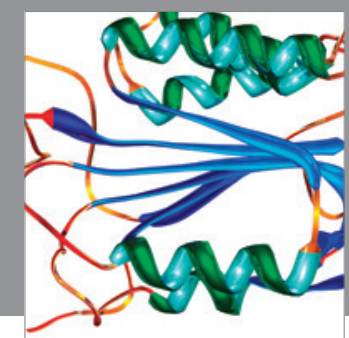

Disease Markers
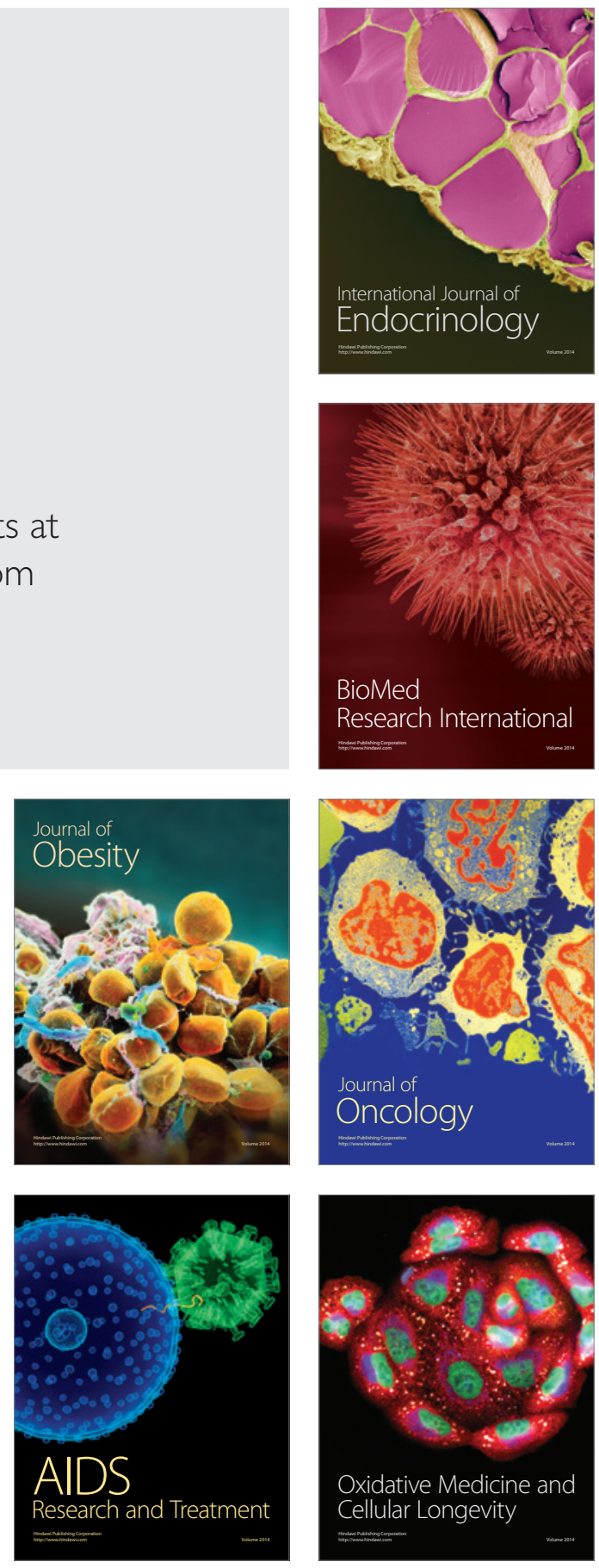